\title{
Belphégor
}

\section{Le soleil médiatique se lève aussi à l'est : notes de travail pour prolonger l'exploration}

Jacques Migozzi

\section{(2) OpenEdition}

1 Journals

\section{Electronic version}

URL: https://journals.openedition.org/belphegor/2624

DOI: 10.4000/belphegor.2624

ISSN: 1499-7185

Publisher

LPCM

\section{Electronic reference}

Jacques Migozzi, "Le soleil médiatique se lève aussi à l'est : notes de travail pour prolonger l'exploration", Belphégor [Online], 18-1 | 2020, Online since 07 February 2020, connection on 30 June 2021. URL: http://journals.openedition.org/belphegor/2624 ; DOI: https://doi.org/10.4000/belphegor. 2624

This text was automatically generated on 30 June 2021.

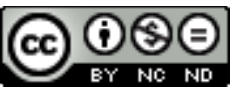

Belphégor est mis à disposition selon les termes de la Licence Creative Commons Attribution - Pas d'Utilisation Commerciale - Pas de Modification 4.0 International. 


\title{
Le soleil médiatique se lève aussi à l'est : notes de travail pour prolonger l'exploration
}

\author{
Jacques Migozzi
}

1 En prenant l'initiative de soutenir scientifiquement et matériellement l'organisation du colloque de Debrecen de 2015, dont ce numéro de Belphégor recueille les Actes, l'équipe de Limoges, en cheville avec l'Association internationale LPCM, souhaitait, entre témérité programmatique et volontarisme opiniâtre, ouvrir un nouveau front des études pluridisciplinaires de grande ampleur qui explorent, depuis plus de 25 ans, les phénomènes multiples et complexes, de la production aux usages, qu'on rassemble communément depuis la fin des années 1990 sous la notion de "culture médiatique ». Il s'agissait en effet de passer à l'acte, suite à l'un des constats majeurs établis à l'issue du projet collectif EPOP ( Popular Roots of European Culture through Films, Comics and Serialized Literature ) et de son prolongement réflexif et méthodologique par le colloque de Louvain de 2011 « Les racines populaires de la culture européenne $»^{1}$ : notre vision de la culture médiatique est peut-être indument occidentalo-centrée sur le plan théorique, faute d'études systématiques menées sur la nouvelle donne culturelle et sociale qu'ont, à leurs manières spécifiques, connu eux aussi les pays et nations de l'Europe centrale, orientale et balkanique, du mitan du XIXème siècle jusqu'à nos jours. Il s'agissait donc de s'aventurer de manière pionnière dans l'inconnu de territoires quasiment vierges de toute recherche académique. Ce que nous rapportons de cette première expédition est - mais pouvait-il en être autrement ? - tout à la fois frustrant et stimulant, roboratif et vertigineux. Car bien sûr, à l'issue de ces quelques coups de sonde, tout reste à faire, ou presque ${ }^{2}$.

2 Grâce à cette première salve d'études sectorielles convergentes, nous avons en effet, conformément à nos espoirs de départ, vu émerger de nouveaux corpus, jusque là ignorés ou à tout le moins non recensés de manière systématique, en particulier celui des romans populaires traduits qui, pièce maîtresse d'une logique d'import-export acculturant au XIXème siècle et jusqu'à l'Entre-deux guerres au moins, participent 
d'une circulation transnationale des récits et des imaginaires. Par leurs annexes bibliographiques et/ou leur visée panoramique, les études de Marcela Poucova sur les traductions tchèques ou slovaques de romans français, ou de Nikos Filippaios sur les imprimés grecs pour la jeunesse des années 1950 et 1960, font ainsi pendant au quadrillage mené par Paul Bleton sur le genre du roman de guerre publié en français depuis la seconde guerre mondiale, ou au repérage minutieux ${ }^{3}$ par Angels Santa et Carme Figueirola des romans de Paul Féval ou de George Sand traduits en espagnol. Les études, fondées sur des dépouillements d'archives et proposant des éléments de synthèse inédits, de Sandor Kalaï sur le cas hongrois, de Norbert Bachleitner sur le cas autrichien, ou encore de Kirill Chekalov sur le cas russe, éclairent pareillement d'un jour nouveau les prémices de la culture médiatique dans les empires austro-hongrois et russe au milieu du XIXème siècle. Tous ces articles nous indiquent donc un cap, celui d'une investigation patiente, minutieuse, de (très ) longue haleine, et surtout collective, car la radiographie de la culture médiatique aux XIXe et XXe siècles en Europe centrale, orientale et balkanique n'est bien sûr ici qu'esquissée et ne peut qu'avouer ses immenses lacunes: en termes de "couverture» chronologique, le balayage/balisage effectué ici porte essentiellement sur la phase initiale d'émergence au XIXe et jusqu'au premier conflit mondial (donc paneuropéen) et seules les contributions de Flitouris et Dermentzopoulos et de Filippaios insistent sur la phase d'expansion qui, des années Trente aux sixties, voient monter en puissance une culture médiatique marquée du sceau de l' "américanisation", que celle-ci soit désirée ou rejetée; en matière de " couverture " géographique, les terra incognita sont tout aussi massives, puisque ce numéro ne propose pour le XXe siècle aucune étude portant sur l'URSS et plusieurs des états du défunt «bloc de l'Est » (Pologne, Tchécoslovaquie ). Sans parler des mutations majeures de la culture médiatique induites, après 1989 et la chute du mur de Berlin, dans les pays du Pacte de Varsovie par le triomphe d'un capitalisme néolibéral débridé : mais ceci est encore une autre affaire, que le colloque de Debrecen n'avait pas dans sa ligne de mire.

3 Reste que, malgré ces lacunes inévitables, ce dossier soulève chemin faisant des questions que des recherches ultérieures pourront saisir au vol. On se permettra ici d'en pointer quelques-unes, fût-ce de manière expéditive.

Tout d'abord, on pourra épingler au moins deux spécificités de la culture médiatique européenne à l'est d'une ligne Allemagne/Italie (pour le dire schématiquement). D'une part, et sur ce point les constats de Bachleitner sur l'Autriche et de Poucova sur la Tchécoslovaquie sont convergents, l'importation par traduction des littératures populaires étrangères semble toujours, dans la mosaïque pluriculturelle et plurilinguistique de l'empire austro-hongrois, impulsée par le pôle hétéronome du champ littéraire - pour reprendre la terminologie bourdieusienne mobilisée par Pascale Casanova dans sa théorisation des transferts culturels ${ }^{4}-$, et ce à des fins nationales, sinon nationalistes. Cette dimension intrinsèquement politique des phénomènes de traduction, marqueurs et vecteurs d'une sécession symbolique avec la langue du dominant, et qui ne seraient donc pas seulement redevables de la logique économique d'un "marché commun» européen de la fiction dominé par la concurrence des deux superpuissances diagnostiquée par Franco Moretti ${ }^{5}$, pourrait singulariser les pays de l'Europe centrale.

5 Un chantier probablement encore plus vaste ne connaît de même ici qu'un début de balisage partiel : celui de la culture de masse imposée, prescrite et modélisée à des fins 
de propagande par les états du bloc de l'est. Il s'agira en effet d'une part de décrire et de penser la spécificité de cette culture de masse dans ses rapports avec la culture populaire traditionnelle : Vilmos Keszeg montre bien dans sa contribution à quel point le folklore national fut, selon les pays et de manière ambivalente, tout à la fois récupéré et instrumentalisé par le régime ou au contraire revendiqué, dans une logique de dissidence manifeste, comme alternative à la culture officielle. Il conviendra d'autre part, comme le soulignent de manière programmatique Lampros Flitouris et Christos Dermentzopoulos, de documenter de manière précise la manière dont se sont articulées pendant des décennies dans les pays situés à l'est du rideau de fer la culture de masse prétendument communiste, impulsée par le régime, et la culture médiatique à la mode occidentale, i.e. une culture médiatique portée par des industries culturelles au sein d'une économie de marché capitaliste. Car - n'en doutons pas - par delà les prescriptions et proscriptions officielles, récusant les produits considérés comme idéologiquement toxiques d'une culture médiatique occidentale américanisée, les récits circulant de manière multimédiatique dans les pays de l'est jusqu'à la fin des années 1980 ont nécessairement pris en compte, entre imprégnation implicite et dénégation, les représentations et imaginaires promus par la culture médiatique de l'Amérique du Nord et de l'Europe de l'Ouest. Lampros Flitouris et Christos Dermentzopoulos signalent au passage deux exemples de ces phénomènes de démarcation sur fond de parenté structurelle : la science-fiction bulgare porte ainsi un message plus optimiste que la SF occidentale, volontiers dystopique, car dans une logique de guerre froide l'épopée spatiale ou scientiste ne doit pas saper le credo dans des lendemains qui chantent ...; de manière similaire les récits policiers de l'est, s'ils décalquent leurs homologues occidentaux, avec par exemple la série bulgare organisée autour du contre-espion Avakum Zahov, «vrai héros de pop-culture», ne peuvent objectivement être considérés comme une « littérature de la crise » selon la définition proposée par JeanPatrick Manchette pour qualifier le polar occidental né du hardboiled américain.

6 Si la culture médiatique "de l'est » affiche d'indubitables spécificités- en termes de tempos, de produits, d'acteurs, d'usages ... - sa mise en regard avec les variantes occidentales de la même (?) culture médiatique se révèle en tous cas fructueuse. Par le décentrement qu'elle induit vis-à-vis des périodisations et cadres théoriques de la culture médiatique forgés par extrapolation universalisante à partir des seules réalités ouest-européenne et nord-américaine, l'étude de la ou plutôt des cultures médiatiques de l'Europe centrale, orientale et balkanique, agit par effet-retour comme un révélateur des facettes de la culture médiatique de l'ouest qui auraient été oubliées ou dont l'importance aurait été méconnue. Ainsi du pouvoir popularisant des médias fondés sur la performance, comme le théâtre ou la littérature orale, qui ont participé de l'avènement d'une première culture médiatique pré audio-visuelle, et ont subsisté bien plus longtemps qu'on ne le postule souvent, malgré l'hégémonie médiatique du cinéma et de la radio d'abord, de la télévision ensuite. Sait-on par exemple qu'en France, au cœur du marais poitevin, des années 1950 aux années 1970, des pièces de théâtre adaptées de quelques grands succès du roman populaire (Les Misérables, Le comte de Monte Cristo, Les deux Orphelines...) ou écrites par des plumitifs catholiques étaient jouées par des troupes locales de théâtre amateur dans le cadre de soirées paroissiales, et drainaient quasiment toute la population du village ?

7 Balayer tout le spectre des fictions populaires dans l' espace européen « de l'Atlantique à l'Oural » - pour reprendre au vol la fameuse formule gaullienne - conduit de plus à réactiver un questionnement récurrent sur leur efficience idéologique. Cette puissance 
de modélisation des imaginaires et des consciences, à des fins d'édification ou de domination symbolique, a été naguère, en 2006 et 2007, longuement scrutée lors du cycle de rencontres internationales de Limoges « Idéologie et stratégies argumentatives dans les récits imprimés de grande consommation. XIXe-XXIe siècles ${ }^{7}$. On retrouve certains échos des débats d'alors dans certaines contributions du présent numéro: Norbert Bachleitner souligne par exemple que les romans publiés par la presse populaire autrichienne véhiculent par ressassement une axiologie très normative, qui vise à prévenir les lectrices de tomber dans la faute, faute du désir, faute de l'hybris qui les pousserait à ne pas se contenter du statu quo social..., rien que du classique pour qui a fréquenté les romans mélodramatiques dont le XIXe siècle fit des best-sellers et qui a lu les études de certains pionniers comme René Guise, Michel Nathan, ou Ellen Constans $^{8}$; mais le même Bachleitner conclut peu après que le roman populaire, dans une logique de divertissement amoral, «permet aussi de jouir de la transgression des normes dans la fiction littéraire ", retrouvant par là la thèse fortement défendue par Matthieu Letourneux et d'autres (dont l'auteur de ces lignes) sur l'ambivalence inhérente aux mauvais genres, dont la lecture délectable est tissée de " mauvaise foi »".

A dire vrai, l'un des acquis majeurs de la présente livraison tient sans doute précisément à ce que plusieurs contributions nous permettent de ne plus seulement penser la culture médiatique en termes de représentations mais bien plutôt en termes de supports et de formats, qui s'avèrent matriciels dans la construction des architextes multimédiatiques. Matthieu Letourneux soutient cette thèse avec force et on ne peut que lui donner raison lorsqu'il affirme qu'avec la déferlante des dime novels sur l'Europe, orchestrée dans les années 1900 et 1910 par la maison d'édition allemande Eichler via ses succursales européennes, c'est moins un nouveau genre de récits qu'un nouveau genre de publications (sérielles, courtes, peu chères, à couverture illustrée tape-à-l'œil, visant un public-cible juvénile...) qui frappe les trois coups d'une nouvelle donne irréversible, nouvelle donne qu'on qualifie peut être un peu hâtivement d' "américanisation" puisque sa dynamique industrielle tient pour une part non négligeable à des initiatives et innovations made in Europe. Reste que, pour bien appréhender les enjeux de cette " mondialisation à l'ère de la culture sérielle » - pour reprendre le titre d'un article antérieur du même Letourneux ${ }^{10}-$, et notamment pour mieux cerner les phénomènes de "glocalisation ", à l'ouest comme à l'est de l'Europe, qui découlent de l'appropriation par les «séries culturelles" nationales de récits multimédiatiques transnationaux, une mobilisation probablement sans précédent des chercheurs en littératures populaires et cultures médiatiques s'avèrerait à coup sûr indispensable. C'est à cette utopie nécessaire que le présent dossier prétend modestement contribuer.

\section{NOTES}

1. Voir Jacques Migozzi «EPOP import/export: de quelques hypothèses sur la circulation transnationale et transmédiatique des fictions populaires en Europe entre 1840 et 1940 », et id. «EPOP reloaded: de quelques enseignements d'une deuxième campagne de fouilles» in Les racines 
populaires de la culture européenne, Stéphanie Delneste, Jacques Migozzi, Olivier Odaert et JeanLouis Tilleuil dir., Bruxelles : Peter Lang, Forum Europe des cultures vol.8, 2014.

2. Pour une mise en perspective méthodologique complémentaire, on pourra se reporter à Jacques Migozzi, «Les fictions populaires européennes au crible du big data et du distant reading: carnet de fouilles (2008-2015)", in Fictions médiatiques et récits de genre. Pour en finir avec le populaire?, Anne Besson dir., Paris, SFLGC, Collection Poétiques comparatistes, 2016

3. Ce recensement complète utilement un travail similaire mené sur d'autres écrivains et rassemblé en 2006 dans un précédent numéro de revue par les mêmes collègues de l'Université de Lleida : voir Euvres et critiques, XXXI, 2, «La réception de la littérature populaire française en Espagne », Tübingen, Gunter Narr Verlag, 2006.

4. Pascale Casanova, La république mondiale des lettres, Paris, Seuil 1999.

5. Franco Moretti, Atlas du roman européen, Paris, Éditions du Seuil, Coll. La Couleur des idées, 2000.

6. Comme le montre le fonds spécifique hébergé par le Service Commun de la Documentation de l'Université de Limoges à partir d'une collecte et d'une enquête portant au départ sur le village du Gué de Velluire puis élargie progressivement à tout le territoire de la Vendée historique. Voir https://www.unilim.fr/scd/fonds-specifiques/fonds-du-theatre-amateur-vendeen/

7. Roman populaire et idéologie, Jacques Migozzi et Loïc Artiaga dir., Belphégor, Volume 9, $\mathrm{n}^{\circ} 2$, janvier /février 2010, : http://etc.dal.ca/belphegor/

8. Voir par exemple Michel Nathan, Splendeurs et misères du roman populaire, Lyon, Presses universitaires de Lyon, 1990.

9. Voir Jacques Migozzi « Storyplaying: la machine à fabriquer ses histoires et à apaiser son esprit », in Finding the Plot. Storytelling in Popular Fictions, Diana Holmes, David Platten, Loïc Artiaga et Jacques Migozzi dir., Cambridge : Cambridge Scholars Publishing, 2013.

10. Matthieu Letourneux, « La mondialisation à l'ère de la culture sérielle », Romantisme, 2014/1.

\section{INDEX}

Keywords: Europe, Eastern Countries, Hungary, Greece, Czechoslovakia, Bulgaria, Austria, Spain, France, popular literature, popular culture, media culture

Mots-clés: Europe, Pays de l'Est, Roumanie, Hongrie, Grèce, Tchécoslovaquie, Bulgarie, Autriche, Espagne, France, Littérature populaire, culture populaire, culture médiatique

\section{AUTHOR}

\section{JACQUES MIGOZZI}

Jacque Migozzi est Professeur de Littérature française moderne et contemporaine. Au départ spécialiste de Jules Vallès (auquel il a consacré sa thèse) et des écritures romanesques engagées des XIXe et XXe siècles, il a élargi et infléchi ses recherches depuis 1992 en reconnaissant l'importance anthropologique des fictions de grande consommation et en questionnant les hiérarchies symboliques du canon culturel. Ce réexamen critique de ses positions de médiateurprescripteur culturel au cœur de l'institution universitaire l'a conduit en 2000 à soutenir une Habilitation à diriger des Recherches intitulée « Ecriture du peuple, littératures populaires : la 
littérature du XIXe siècle et de la Belle Epoque entre engagement et divertissement ", puis à publier en 2005 un essai de synthèse : Boulevards du populaire. Ses travaux personnels portent plus particulièrement sur des corpus de littérature populaire engagée ou édifiante (ErckmannChatrian, Eugène Le Roy, Le Tour de la France par deux enfants...) ou s'efforcent à des mises au point théoriques et des mises en perspective problématisées, visant à capitaliser les acquis des vingt dernières années de recherches ès populaire et à baliser simultanément de nouveaux chantiers collectifs. 